\title{
The Cardiogenic Niche as a Fundamental Building Block of Engineered Myocardium
}

\author{
Peter Christalla James E. Hudson Wolfram-Hubertus Zimmermann \\ Department of Pharmacology, University Medical Center Göttingen and Heart Research Center Göttingen, \\ Göttingen, Germany
}

\section{Key Words}

Embryonic stem cells • Heart development - Myogenesis • Progenitor cells $\cdot$ Stem cell biology $\cdot$ Cardiac cells $\cdot$ Tissue engineering

\section{Abstract}

Cardiac muscle engineering is evolving rapidly, aiming at the provision of innovative models for drug development and therapeutic myocardium. The progress in this field will depend crucially on the proper exploitation of stem cell technologies. Understanding the processes governing stem cell differentiation towards a desired phenotype and subsequent maturation in an organotypic manner will be key to ultimately providing realistic tissue models or therapeutics. Cardiogenesis is controlled by milieu factors that collectively constitute a so-called cardiogenic niche. The components of the cardiogenic niche are not yet fully defined but include paracrine factors and instructive extracellular matrix. Both are provided by supportive stromal cells under strict spatial and temporal control. Detailed knowledge on the exact composition and functionality of the dynamic cardiogenic niche during development will likely be instrumental to fur-

\begin{tabular}{ll} 
Abbreviations used in this paper \\
\hline BMP & bone morphogenic protein \\
CT-1 & cardiotrophin-1 \\
ECM & extracellular matrix \\
EGF & epidermal growth factor \\
ESCs & embryonic stem cells \\
FGF & fibroblast growth factor \\
GSCs & germline stem cells \\
HB-EGF & heparin-binding EGF-like growth factor \\
IL-6 & interleukin 6 \\
iPSCs & induced pluripotent stem cells \\
LIF & leukemia inhibitor factor \\
MHC & major histocompatibility complex \\
PSCs & parthenogenetic stem cells \\
SSCs & spermatogonial stem cells \\
TGF- $\beta$ & transforming growth factor- $\beta$ \\
VEGF & vascular endothelial growth factor \\
Wnt & wingless/integration 1
\end{tabular}

P.C. and J.E.H. contributed equally to this work.

\section{KARGER \\ Fax +4161306 1234 \\ E-Mail karger@karger.ch}

www.karger.com
(C) 2011 S. Karger AG, Basel

$1422-6405 / 12 / 1952-0082 \$ 38.00 / 0$

Accessible online at:

www.karger.com/cto
Dr. Wolfram-Hubertus Zimmermann

Department of Pharmacology, University Medical Center Göttingen Robert-Koch-Strasse 40

DE-37075 Göttingen (Germany)

Tel. +4955139 5781, E-Mail w.zimmermann@med.uni-goettingen.de 
Fig. 1. Cardiogenic niche in myocardial tissue engineering. Schematic overview of key functionalities of an engineered cardiogenic niche. The configuration of the engineered cardiogenic niche depends on the primary cell source used for myocardial tissue engineering.

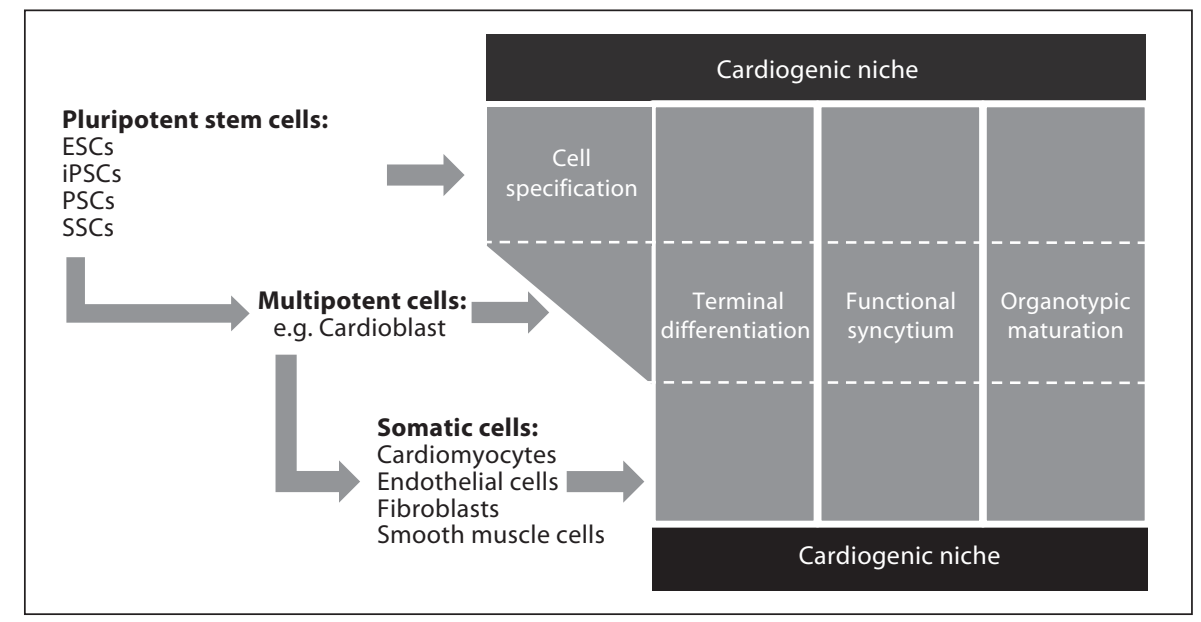

ther advance cardiac muscle engineering. This review will discuss the concept of myocardial tissue engineering from the stem cell/developmental biology perspective and put forward the hypothesis of the cardiogenic niche as a fundamental building block of tissue-engineered myocardium.

Copyright ๑ 2011 S. Karger AG, Basel

\section{Introduction}

Tissue engineering approaches aim at the provision of an artificial tissue mimic with a natural organ structure and function. For use as an in vitro research tool, these mimics must recapitulate the natural organ sufficiently to enable translatable conclusions to be made. For use in therapeutic applications, these mimics must be capable of restoring the function of the damaged organ. While tissue engineering approaches were originally based on the idea of populating preformed polymeric scaffolds [Langer and Vacanti, 1993], the rapidly advancing understanding of the biology associated with natural tissue development has led to the introduction of more complex approaches to ultimately combine engineering principles and knowledge from developmental biology. The exploitation of 'biological' engineering processes will most likely also facilitate myocardial tissue engineering [Zimmermann, 2011].

The process of heart development starts with the commitment of undifferentiated pluripotent stem cells forming lineage-restricted mesodermal derivatives which finally constitute the source for highly specialized myocardial cells, which primarily include cardiomyocytes, endothelial cells, smooth muscle cells, and fibroblasts.
Despite the rapid increase in the understanding of developmental processes, there is still a substantial lack of insight into the environmental conditions controlling cardiogenesis. These likely involve a complex interplay of cellular and extracellular factors, collectively constituting a unique cardio-instructive environment which may be best described as a cardiogenic niche.

Engineering a cardiogenic niche and scaling it to create functional myocardium appears to be a key challenge for tissue engineers. It is important to consider the cardiogenic niche as a highly dynamic milieu with different functionalities depending on both the developmental stage and the normal versus diseased state. During early stages of development, niche factors play an essential role in the interplay between cell expansion and specification, thus controlling not only the cell fate but also the size and shape of heart structures [Prall et al., 2007]. During later developmental stages and also in the postnatal heart, the niche factors facilitate terminal differentiation and maturation. This temporal specificity of the cardiac niche means that the required fundamental factors for a cardiogenic niche as a building block of macroscale tissue-engineered myocardium are determined by the phenotype and maturity of the cell population(s) used. For example, if multipotent cells are utilized, an environment that will support cellular specification along the canonical steps of myocardial development must be provided. Subsequent to specification, induction of terminal differentiation, integration into a multicellular functional syncytium, and organotypic maturation have to be considered (fig. 1). In contrast, if highly specified somatic cells are used as starting material it will be important to mitotically arrest them (i.e. induce terminal differentiation), support their 
Fig. 2. Cardiogenic signaling in the mouse embryo. a Growth factor gradients control primitive streak (PS) formation in the early embryo [embryonic day (ED) 7]. Cardiac progenitor cells migrate through and exit from the PS into the heart-forming mesoderm. b Growth factor gradients control cardiac progenitor specification and differentiation at the cardiac crescent stage (ED 7.5-8; transverse section at the striped line).

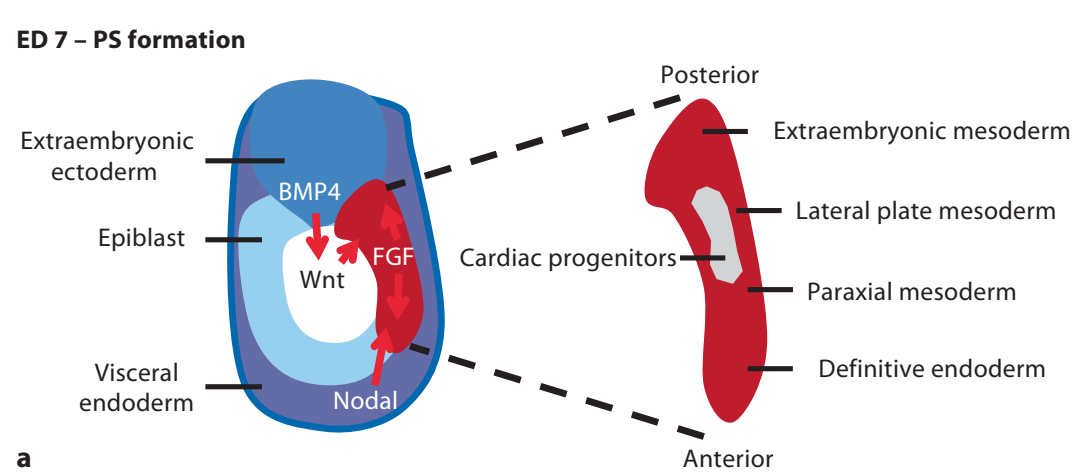

ED 7.5-8 - cardiac crescent formation

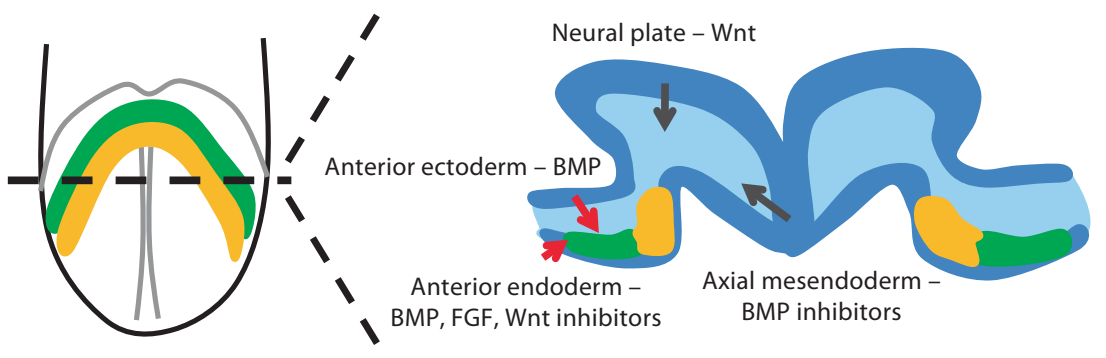

First heart field cells

b Second heart field cells assembly into a functional syncytium, and facilitate organotypic maturation of the newly engineered multicellular tissue.

In this review we first provide background information on factors governing heart development in vivo and the role of the proposed cardiogenic niche with its key constructor 'the cardiac fibroblast'. This is followed by an introduction of available pluripotent stem cell types that may be utilized as starting material for myocardial tissue engineering and an overview of means to direct them into the cardiac lineage. Finally, we discuss the concept of engineering cardiogenic niches as building blocks of tissue-engineered myocardium.

\section{Cardiopoetic Factors in Heart Development}

While it is not the subject of this review to describe heart development in detail, it is important to recognize the principles of in vivo cardiogenesis as an important basis for the facilitation of in vitro heart muscle engineering
[Murry and Keller, 2008]. Heart development is a complex process in which both the activation and the inhibition of signaling pathways is required in defined chronological stages [Noseda et al., 2011]. During development, a process known as gastrulation gives rise to the different germ layers - ectoderm, endoderm, and mesoderm - from which all fetal tissues are derived. The first sign of the gastrulation process is the formation of the primitive streak. Epiblast cells ingress through the primitive streak and are patterned to form different mesodermal and endodermal tissues, while ectodermal tissues are formed by epiblast cells not passing through the primitive streak. The specification and patterning of the primitive streak are known to be mediated through gradients of wingless/integration 1 (Wnt), transforming growth factor- $\beta$ (TGF- $\beta$ ) family proteins [including nodal, bone morphogenic proteins (BMPs), and activin A], and fibroblast growth factor (FGF) signaling (fig. 2a; [Tam and Loebel, 2007]).

Following gastrulation, signals from adjacent endoderm and ectoderm induce cardiomyogenesis in the heart-forming region [Harvey, 2002]. BMP, FGF, nonca- 
Fig. 3. Putatively important fibroblastderived components of the cardiogenic niche.

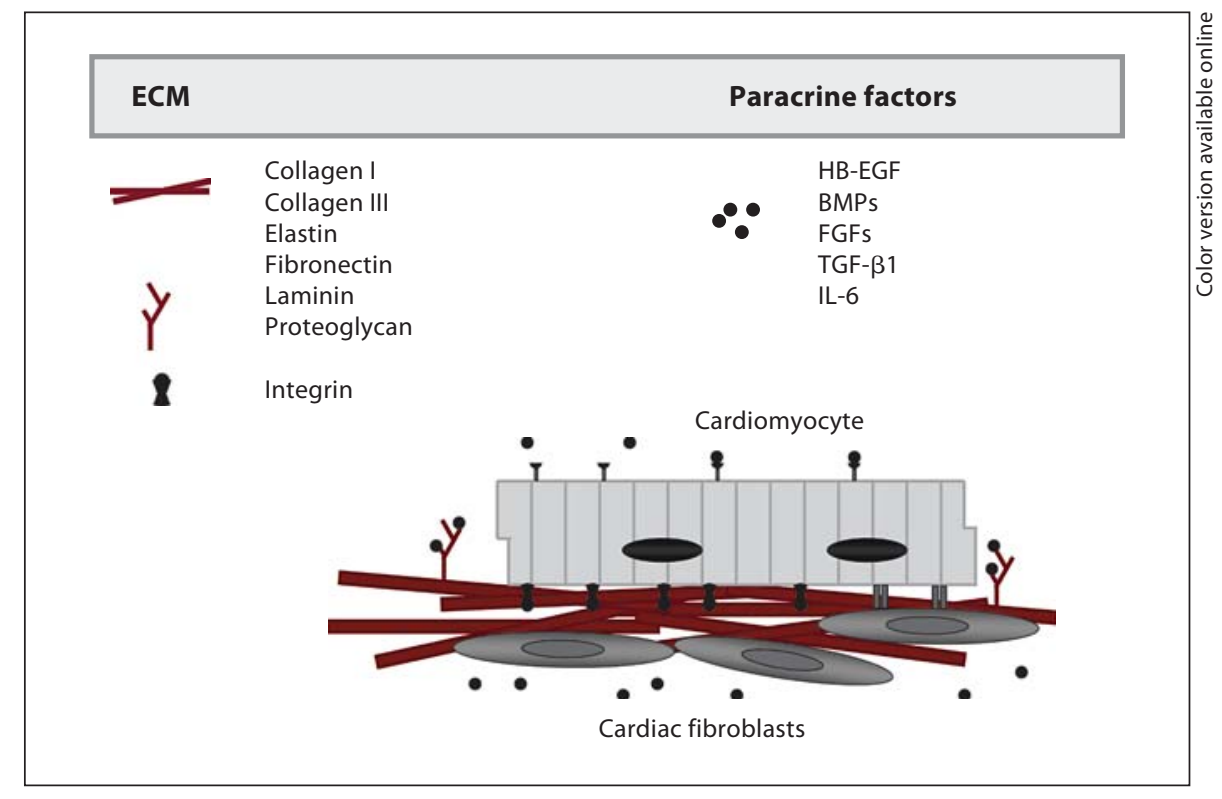

nonical Wnt, hedgehog, notch, and retinoic acid signaling pathways on the one hand and inhibition of canonical Wnt signaling on the other hand have been ascertained to play a role in cardiomyogenesis in the heart-forming mesoderm region [Harvey, 2002; Niessen and Karsan, 2008; Noseda et al., 2011]. Through this process, primary and secondary heart fields are formed (fig. 2b). The primary heart field gives rise to left ventricular and atrial tissue and the secondary heart field appears to be the primary origin of the right ventricle, parts of the atria, and the outflow tract [Olson, 2006; Prall et al., 2007; Dyer and Kirby, 2009]. The adult myocardium can later be subdivided into three morphologically distinct structures: (1) the endocardium, (2) the myocardium, and (3) the epicardium. Both the endocardium and the epicardium provide modulation of key signaling pathways which affect the myocardium in development and postnatal homeostasis [Eid et al., 1992; Brutsaert et al., 1998; Männer, 2006; Limana et al., 2007; Smith and Bader, 2007]. However, the aforementioned developmental processes giving rise to the heart-forming mesoderm only form the endocardial and myocardial layers [Ho and Shimada, 1978; Hiruma and Hirakow, 1989; Virágh et al., 1993]. Interactions between endocardial cells and cardiomyocytes are essential in these processes. These interactions not only control the growth, maturation, and compaction of the myocardium during development but also instruct the formation and organization of the endocardial trabeculae and cardiac valves. In addition, the endocardium has also been dem- onstrated to influence the contractile function of heart muscle. The signaling networks governing these processes are complex and bidirectional between the endocardium and the myocardium [for more detail please refer to an excellent overview by Brutsaert, 2003].

The epicardial layer develops from a mesoderm-derived proepicardial organ [Hiruma and Hirakow, 1989; Virágh et al., 1993; Gittenberger-de Groot et al., 1998]. Following the formation of the two-layered endocardium and myocardium of the heart, cells from the proepicardial organ migrate and cover the outer surface of the heart, creating the 'third' layer [Ho and Shimada, 1978; Hiruma and Hirakow, 1989; Cai et al., 2008]. However, these cells not only give rise to the mesoepithelial cells of the epicardium but apparently also contribute physiologically and partially also under pathological conditions to the fibroblast, smooth muscle cell, endothelial cell, and cardiomyocyte populations of the myocardium [Mikawa and Gourdie, 1996; Gittenberger-de Groot et al., 1998; Tevosian et al., 2000; Cai et al., 2008; Smart et al., 2011].

\section{The Cardiogenic Niche and the Cardiac Fibroblast}

Developmental processes in the heart are likely facilitated through defined cardiogenic niches. The structural components of a cardiogenic niche are not fully defined but include in general progenitors, derivatives thereof, 
stromal cells, and extracellular matrix (ECM). Cardiogenic niche composition and functionality likely change during development to govern heart muscle formation in the early embryo, differentiation of myocardial tissue in the fetus, and myocardial homeostasis in the postnatal heart. Fibroblasts appear to play a key role for the cardiogenic niche as they 'construct' a cardioinstructive ECM environment and provide important growth factors as well as cytokines (fig. 3).

\section{ECM and Fibroblast-Secreted Growth Factors during Embryonic Heart Development}

The knowledge of the role of the ECM during heart development is still limited. It has been recently demonstrated in the mouse that cardiac fibroblasts arise in the embryonic heart around embryonic day 12.5 and subsequently increase in number during development [Ieda et al., 2009]. During this stage of heart development embryonic cardiac fibroblasts produce a complex ECM environment (including fibronectin and collagens), which stimulates proliferation of immature cardiomyocytes through $\beta 1$-integrin signaling [Ieda et al., 2009]. Other fibroblast-derived factors involved in the induction of cardiomyocyte proliferation include, for example, heparin-binding epidermal growth factor-like growth factor (HB-EGF) [Ieda et al., 2009]. Additionally, several other fibroblast-specific molecules have been identified to be involved in cardiomyogenesis, including members of the FGF family, TGF- $\beta 1$, and cytokines of the interleukin-6 (IL-6) family [Wollert and Chien, 1997; Dell'Era et al., 2003; Cohen et al., 2007]. Importantly, the fibroblast-derived microenvironment changes during development to promote the stage-specific processes of specification, differentiation, integration, and maturation of the cardiomyocytes and their precursors [Ieda et al., 2009].

\section{The ECM Entails a Structural and Regulatory \\ Function}

The ECM of the heart is mainly recognized as a structural scaffold, embedding and supporting cardiomyocytes and nonmyocytes. However, detailed analysis of the ECM components provided a more complex insight into the biological and regulatory function of the cardiac ECM. The heart ECM consists of: (i) structural proteins (e.g. collagens and elastins), (ii) adhesive proteins (e.g. laminin and fibronectin), and (iii) proteoglycans. Myocardial cells can biologically and mechanically communicate directly with this ECM network through highly specific transmembrane receptors (integrins) and their corresponding ECM binding domains [Samarel, 2005]. Integrins are heterodimeric receptors comprised of one $\alpha$ and one $\beta$ subunit. Different combinations of $\alpha$ and $\beta$ subunits provide a wide range of specificities for different ECM binding motifs [Samarel, 2005]. Different binding motifs are present on different ECM proteins and some proteins may contain an array of different binding motifs. For example, collagen fibers contain sequence motives specific for $\alpha 1 \beta 1-, \alpha 2 \beta 1-, \alpha 10 \beta 1-$, and $\alpha 11 \beta 1$-integrins [Jokinen et al., 2004]. Binding of ECM to its specific integrins will activate signaling cascades with a potential role in cell fate regulation.

The interstitial ECM network within the myocardium is composed predominantly of structural collagen types I and III, which are mainly produced by cardiac fibroblasts [Weber, 1989]. Laminin is also present and contains multiple epidermal growth factor (EGF)-like domains capable of binding to EGF receptors and modulating EGF signaling [Engel, 1989; Hynes, 2009]. Other ECM components including proteoglycans are also found in the heart and are capable of binding and regulating the function of secreted growth factors including vascular endothelial growth factor (VEGF), FGFs, BMPs, and TGF- $\beta 1$ [Shi and Massagué, 2003; Wijelath et al., 2006; Wang et al., 2008]. This propensity of the ECM to influence growth factor signaling indicates that the ECM provides not only structural and mechanical properties of the myocardium, but also the regulation of key biological signaling pathways.

\section{Paracrine Communication between Fibroblasts and Cardiomyocytes}

Cardiac fibroblasts secrete a variety of factors that control muscle growth [Ieda et al., 2009; Noseda and Schneider, 2009; Noseda et al., 2011]. Currently, the understanding of these interactions is limited, also due to the difficulty in creating transgenic animals with specific modifications in heart fibroblasts. However, cell culture experiments have identified several fibroblast-derived factors, including members of the FGF, TGF, and IL-6 families.

FGF family members have been identified to mediate bidirectional fibroblast-cardiomyocyte cross talk, which can lead to physiological and pathological growth of cardiomyocytes [Lopez-Sanchez et al., 2002; Dell'Era et al., 2003; Cohen et al., 2007]. Cardiac fibroblast-secreted FGF2 is capable of binding to ECM-proteoglycans and other components of the basement membrane [Kardami et al., 2007]. It exists in several molecular weight forms [Liao et al., 2009]. The higher-molecular weight FGF2 is 
Fig. 4. Pluripotent stem cell sources for tissue engineering applications. ESCs and PSCs can be derived from the inner cell mass of an embryonic or parthenogenetic blastocyst, respectively. Reprogramming of apparently any somatic cell towards an ESC-like state can be achieved by transcription factor-mediated epigenetic mechanisms. Male SSCs can give rise to pluripotent germ line stem cells under appropriate cell culture conditions.

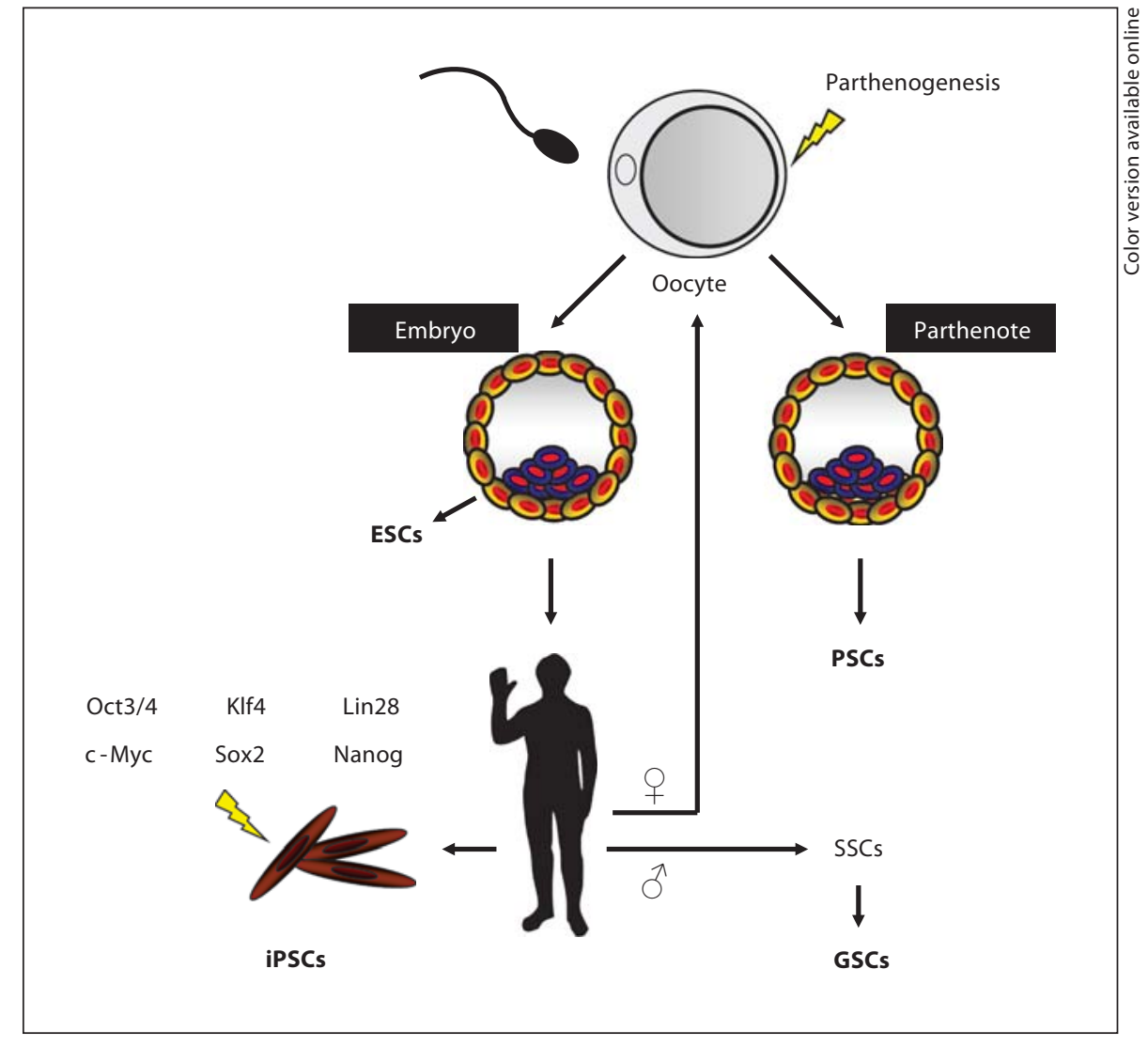

predominantly expressed by embryonic and adult cardiac fibroblasts and has been shown to induce a fetal gene program and promote hypertrophy in cardiomyocytes [Jiang et al., 2007]. In contrast, the lower-molecular weight FGF2 is involved in the homing and differentiation of progenitor cell populations and influences cell fate decisions of resident stem cells toward the cardiomyocyte lineage [Rosenblatt-Velin et al., 2005; Kardami et al., 2007; Takehara et al., 2008].

Signaling via TGF- $\beta 1$ has not only been linked to fibrosis and hypertrophy in the heart but it is also involved in cardiomyocyte differentiation. It has been demonstrated that human cardiomyocyte progenitor cells preferentially differentiate into cardiomyocytes under TGF$\beta 1$ stimulation [Goumans et al., 2008]. In the adult heart, TGF- $\beta 1$ is associated with cardiomyocyte hypertrophy and its expression is upregulated in pressure overload and myocardial infarction [Takahashi et al., 1994; Bujak and Frangogiannis, 2007; Kakkar and Lee, 2010]. Moreover, TGF- $\beta 1$ modulates the fibroblast phenotype and gene expression, promoting ECM deposition, for example, in infarcted myocardium by upregulating collagen and fibro-

Engineered Cardiogenic Niche nectin synthesis and decreasing matrix degradation through induction of ECM protease inhibitors [Bujak and Frangogiannis, 2007].

Members of the IL- 6 family are also mainly secreted from cardiac fibroblasts and have been demonstrated to play an important role during cardiac development and postnatally for cardiomyocyte growth [Banerjee et al., 2009]. The biological activity of IL- 6 is regulated by the transmembrane receptor subunit gp130, and continuous stimulation with IL- 6 or other members of the IL- 6 family, including leukemia inhibitor factor (LIF) and cardiotrophin (CT-1), leads to cardiac hypertrophy [Hirota et al., 1995]. Transgenic gp130 knockout mice die in early stages of development due to a failure to develop compact myocardium [Wollert and Chien, 1997]. However, mice with conditional ventricular knockout of gp130 receptors have a normal heart structure and function, but during pressure overload they exhibit accelerated dilated cardiomyopathy and massive cardiomyocyte apoptosis [Hirota et al., 1999]. This suggests that signaling through gp130 is critical for cardiomyocyte survival in pathologic conditions. 


\section{Pluripotent Stem Cells for Myocardial Tissue Engineering}

Myocardial tissue engineering greatly benefits from the rapid advances in stem cell biotechnology. Pluripotent stem cells - such as embryonic stem cells (ESCs), induced pluripotent stem cells (iPSCs), spermatogonial stem cells (SSCs), and parthenogenetic stem cells (PSCs; fig. 4) - have the unique propensity to differentiate into all somatic cell types, including bona fide cardiomyocytes [Kehat et al., 2001; Guan et al., 2007; Mauritz et al., 2008]. Of particular additional interest to cardiac tissue engineers is that pluripotent stem cells can be subjected to cardiogenic bulk cultures to produce large quantities of cardiomyocytes [Schroeder et al., 2005], being a prerequisite for myocardial tissue engineering.

ESCs represent the prototypic pluripotent stem cell. They were first isolated in the early 80 s from the inner cell mass of mouse blastocysts [Evans and Kaufman, 1981; Martin, 1981]; this was followed by the establishment of the first human ESC lines nearly two decades later [Thomson, 1998]. Their unlimited self-renewing capacity does in principle allow indefinite expansion of ESCs if cultured cells remain (epi)genetically and developmentally stable. Interestingly, allogeneic transplantation of human ESC-derived cell products has recently reached the stage of clinical investigation despite widely discussed ethical and immunological concerns [Razvi, 2010]. These treatments will most certainly require lifelong immune suppression to control host-versus-graft reactions [Opelz et al., 1999; Drukker et al., 2002; Swijnenburg et al., 2008]. Perfect host-donor matching for immunologically relevant major histocompatibility complex (MHC) proteins may in principle address this shortcoming but is unrealistic in terms of practicability. This caveat and the ethical controversy associated with human ESC derivation have led to intense research to generate patient-specific nonembryonic but developmentally ESClike stem cells.

The pluripotent state of ESCs is controlled through a network of stemness factors [Niwa, 2007] and this knowledge has been the basis for the recently developed somatic cell reprogramming technologies [Takahashi et al., 2007; Yu et al., 2007]. The original reprogramming technologies involved retroviral transduction of defined sets of stemness factors [Takahashi et al., 2007]. Coupled with the inherent risk of genetic mutations associated with viral integration, there is also a risk of tumor/teratoma formation if the delivered genes remain active or are reactivated in vivo. The risk of pluripotent gene reac- tivation has already been successfully reduced by generating iPSCs using a reduced number of pluripotency factors [Kim et al., 2009], using nonintegrating DNA delivery systems [Stadtfeld et al., 2008], and reprogramming with recombinant proteins [Zhou et al., 2009] as well as RNA [Yakubov et al., 2010] or (at least in part) with small molecules [Shi et al., 2008]. However, reprogrammed iPSCs appear to harbor an epigenetic memory of their original somatic cell state, which may skew their differentiation potential towards the original somatic cell source lineage [Kim et al., 2010]. To overcome this epigenetic barrier, differentiation followed by serial reprogramming, the use of chromatin-modifying drugs, or prolonged culture times has been proposed [Kim et al., 2010]. In the future, exclusively pharmacological reprogramming may be preferable; however, a better understanding of the molecular mechanisms underlying the epigenetic reprogramming process and its stability is essential.

Under appropriate in vitro culture conditions embryonic primordial germ cells are able to convert into pluripotent stem cells [Cooke et al., 1993], thus conceptually also enabling the generation of patient-specific stem cells without genetic modification. Male germ cells physiologically develop into unipotent SSCs. However, SSCs from adult mice cultured under standard ESC conditions can acquire the ability to differentiate into cell types of the three germ layers, including functional cardiomyocytes [Guan et al., 2006]. Whether human SSCs are also able to convert into pluripotent germline stem cells (GSCs) remains unclear [Conrad et al., 2008; Ko et al., 2010].

Female primordial germ cells develop already prenatally into a definitive quantity of primary oocytes which remain meiotically arrested until sexual maturity. In mammals, unfertilized oocytes can be activated to divide pharmacologically by stimulation of calcium waves which are normally associated with fertilization [Swann and Ozil, 1994]. These asexually activated oocytes can develop into parthenogenetic blastocysts, containing an inner cell mass composed of pluripotent PSCs [Kim et al., 2007].

\section{Recapitulating Cardiogenesis in Pluripotent Stem Cells}

Although pluripotent stem cells have the ability to undergo robust cardiomyogenesis, undirected differentiation of ESC in embryoid bodies yields notoriously low 


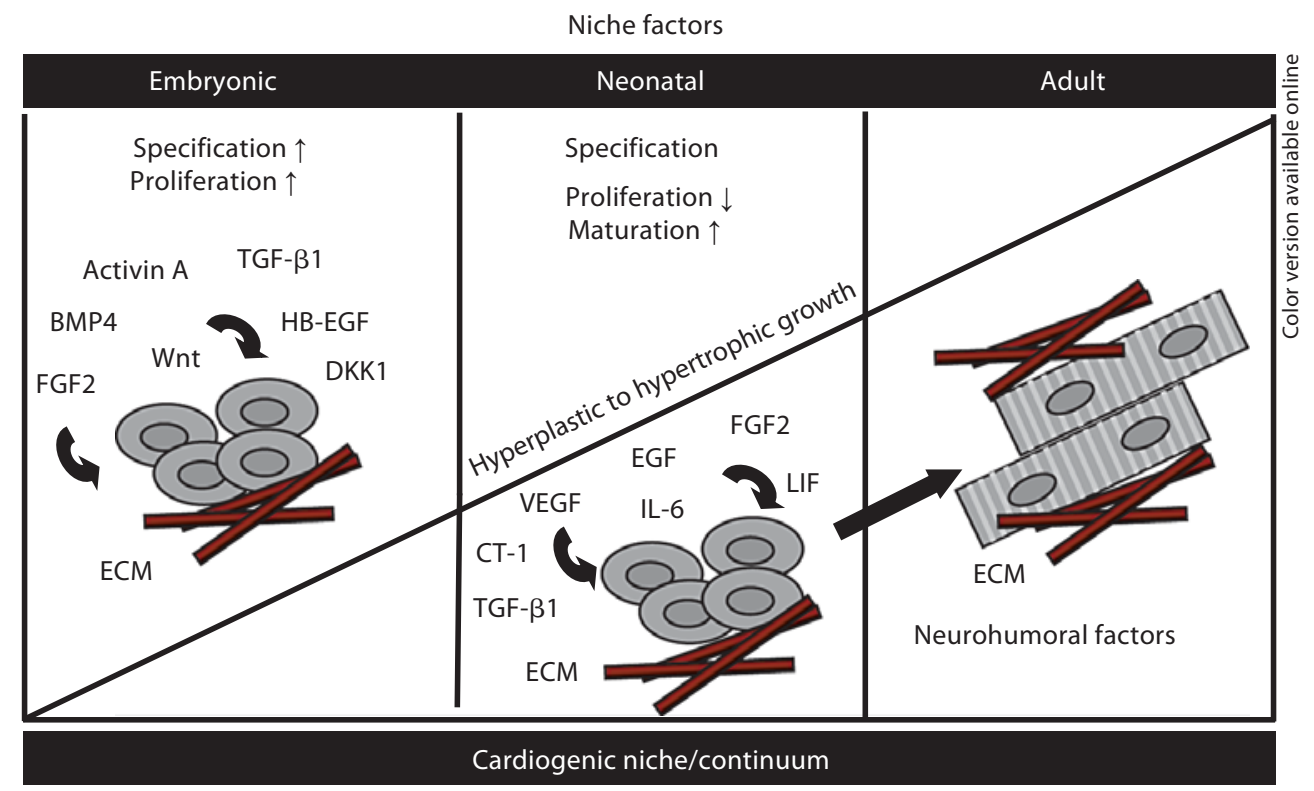

Fig. 5. Schematic overview of cardiogenic niche factors and niche development from the embryo to the adult. Specification and proliferation as well as maturation of immature cardiomyocytes are regulated by niche factors. Key factors known to play an important role during embryonic, neonatal, and adult stages may also be used to engineer mature tissue equivalents from pluripotent stem cell sources. The adult niche is structurally and functionally not well defined. It appears plausible that the developmentally essential and spatially defined embryonic cardiogenic niche transforms into a less spatially defined hypertrophic growth and cell survival controlling cardiogenic continuum in the adult. This may also go hand in hand with a shift from local paracrine to more (neuro)humoral control of niche/continuum functionality. A better understanding of the embryonic cardiogenic niche and the adult cardiogenic continuum will be essential to advance tissue engineering and in particular construction of mature bioartificial myocardium. cardiomyocytes quantities [Klug et al., 1996; Kehat et al., 2001; Wobus et al., 2002]. This has led to directed differentiation strategies and their broad utilization to improve cardiomyogenesis in pluripotent stem cells [Mummery et al., 2003; Laflamme et al., 2007; Yang et al., 2008; Kattman et al., 2011]. Coculture of human ESCs with an endodermal-like cell line (END-2) can, for example, improve cardiomyocyte derivation [Mummery et al., 2003], which is consistent with developmental processes where secreted growth factors from the visceral endoderm are important for the induction and sustainment of heart development [Smith et al., 1990; Sugi and Lough, 1994]. Growth factors that are secreted from the endoderm and mediate these effects are members of the TGF- $\beta$ superfamily, including activin-A and BMP4 [Lough et al., 1996; Ladd et al., 1998; Barron et al., 2000; Nakajima et al., 2002; Swijnenburg et al., 2008]. Further demonstrating the potency of these factors, utilization of activin-A and BMP4 in a defined medium can result in a cardiomyocyte induction efficiency of up to $33 \%$ [Laflamme et al., 2007]. Other essential cardiogenic signals have been used to improve hESC cardiomyocyte differentiation, including those which modulate the FGF and Wnt pathways. While FGF signaling (via FGF2) stimulates the proliferation of cardiac progenitors through activation of the MAP kinase pathway [Mima et al., 1995], the canonical Wnt pathway must be blocked in order to specify cardiac progenitor development. Accordingly, the supplementation of the Wnt-antagonist Dickkopf-1 (DKK1) after primitive streak cell specification gives rise to a substantial increase in cardiomyocyte differentiation efficiency in hESC cultures [Yang et al., 2008]. The concept to learn from natural cardiogenesis appears to be superior to unbiased screening of compounds as the latter approach has led to the identification of many potentially cardiomyogenesis-inducing factors but little acceptance of a standard stem cell differentiation protocol. This may at least in part be due to the necessity to not only identify a potential trigger but also understand the strict temporal control of myocardial differentiation processes. 


\section{The Cardiogenic Niche as a Fundamental Building Block of Engineered Myocardium}

The importance of understanding developmental processes that govern natural heart development becomes apparent when constructing tissue-engineered myocardium from pluripotent stem cell derivates. Here, simulating processes that are naturally confined to the cardiogenic niche (fig. 5) would likely be desirable. In addition, developmental changes in cardiogenic niche functionality will have to be considered to achieve cell specification as well as terminal differentiation early on and subsequently support maturation. Specification and differentiation inducing growth factors and cytokines naturally provided through the cardiogenic niche have been readily identified and are widely used to enhance cardiogenesis in pluripotent stem cells [Laflamme et al., 2007; Yang et al., 2008; Zhang et al., 2009; Paige et al., 2010; Zhu et al., 2010; Kattman et al., 2011]. On the other hand, the definition of factors controlling advanced maturation is limited. Considerable effort has been directed toward the design of instructive scaffolds that may impose mechanical stimuli but also biological cues on developing cardiomyocytes [Murtuza et al., 2009; Schenke-Layland et al., 2011]. Moreover, it is likely that different scaffold fabrication technologies can be combined to generate instructive matrices with biophysical and biological properties that guide cell specification, differentiation, and maturation. Synthetic polymers may be useful in this respect as they can be easily designed with defined biomechanical properties and geometry [Bursac et al., 1999; Carrier et al., 1999]. However, native ECM appears to be better suited for designing a more physiological cardiogenic niche, as exemplified by studies utilizing ECM hydrogels to entrap heart cells in a 3-D fibrillar network [Zimmermann et al., 2004; Guo et al., 2006]. Growth factor conditioning, electrical stimulation, and addition of nonmyocytes can be used to further optimize natural hydrogel-based tissue constructs [Zimmermann et al., 2002; Radisic et al., 2004; Naito et al., 2006]. Provision of bioactive molecules such as VEGF to induce vascularization of engineered tissue equivalents has attracted particular attention [Helm et al., 2007]. Alternatively, supplementation with endothelial cells has been exploited to enhance vascular network formation in bioengineered myocardium [Caspi et al., 2007; Tulloch et al., 2011]. Moreover, fibroblast supplementation markedly improved not only the functionality but also the capillarization of engineered heart tissue [Naito et al., 2006]. Collectively, there is ample evidence that heart muscle engineering will benefit from integrating all components of the cardiogenic niche (i.e. cells, matrix, and biophysical and biological stimuli) to foster heart muscle formation in particular from pluripotent stem cells or cardiomyogenic progenitors. As the cardiogenic niche is a spatially defined structure with the capacity to generate de novo myocardium, exploiting its properties in myocardial tissue engineering appears reasonable. Moreover, maintaining the principle properties of the cardiogenic niche in a spatially less restricted 'cardiogenic continuum' appears to be essential to facilitate formation of a mature myocardial syncytium.

\section{Conclusion}

Concepts to successfully generate myocardium in vitro have been established over the past 15 years. These concepts have now advanced to a stage where engineered myocardium can be constructed and delivered in vivo for experimental purposes and have constituted a premise for potential therapeutic use in the future [Zimmermann et al., 2006; Tulloch et al., 2011]. While original studies have previously mainly employed primary cells, stem cells have become the preferred starting material in myocardial tissue engineering. Stem cells are capable of producing all of the required cell types to biologically engineer complex multicellular myocardium. The broad utility of stem cells and their derivatives will depend on advances in protocols to control their specification, differentiation, functional integration, and organotypic maturation. We suggest that this can be achieved through the implementation of cardiogenic niche factors in myocardial tissue engineering. Finally, we anticipate that the concept to support heart development in vitro by utilizing the knowledge from developmental biology will allow production of large functional myocardium with structural and functional properties of mature myocardium.

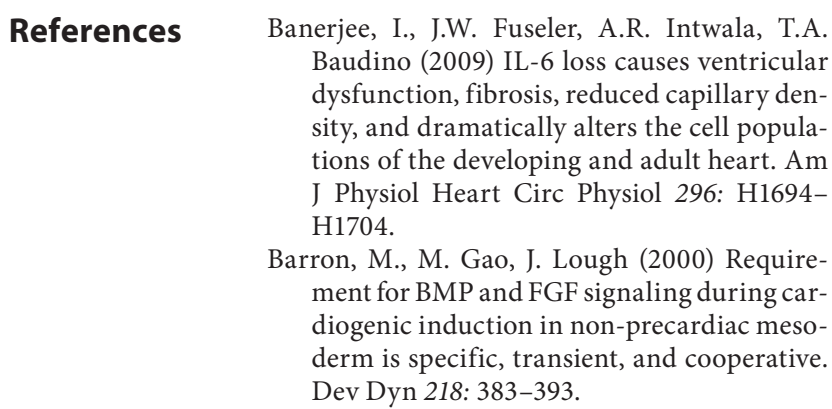

Christalla/Hudson/Zimmermann 
Brutsaert, D.L. (2003) Cardiac endothelial-myocardial signaling: its role in cardiac growth, contractile performance, and rhythmicity. Physiol Rev 83: 59-115.

Brutsaert, D.L., P. Fransen, L.J. Andries, G.W. De Keulenaer, S.U. Sys (1998) Cardiac endothelium and myocardial function. Cardiovasc Res 38: 281-290.

Bujak, M., N.G. Frangogiannis (2007) The role of TGF-beta signaling in myocardial infarction and cardiac remodeling. Cardiovasc Res 74: 184-195.

Bursac, N., M. Papadaki, R.J. Cohen, F.J. Schoen, S.R. Eisenberg, R. Carrier, G. Vunjak-Novakovic, L.E. Freed (1999) Cardiac muscle tissue engineering: toward an in vitro model for electrophysiological studies. Am J Physiol Heart Circ Physiol 277: H433-H444.

Cai, C.L., J.C. Martin, Y. Sun, L. Cui, L. Wang, K. Ouyang, L. Yang, L. Bu, X. Liang, X. Zhang, W.B. Stallcup, C.P. Denton, A. McCulloch, J. Chen, S.M. Evans (2008) A myocardial lineage derives from $\mathrm{Tbx} 18$ epicardial cells. $\mathrm{Na}-$ ture 454: 104-108.

-Carrier, R.L., M. Papadaki, M. Rupnick, F.J. Schoen, N. Bursac, R. Langer, L.E. Freed, G. Vunjak-Novakovic (1999) Cardiac tissue engineering: cell seeding, cultivation parameters, and tissue construct characterization. Biotechnol Bioeng 64: 580-589.

-Caspi, O., A. Lesman, Y. Basevitch, A. Gepstein, G. Arbel, I.H. Habib, L. Gepstein, S. Levenberg (2007) Tissue engineering of vascularized cardiac muscle from human embryonic stem cells. Circ Res 100: 263-272.

Cohen, E.D., Z. Wang, J.J. Lepore, M.M. Lu, M.M. Taketo, D.J. Epstein, E.E. Morrisey (2007) Wnt/beta-catenin signaling promotes expansion of Isl-1-positive cardiac progenitor cells through regulation of FGF signaling. J Clin Invest 117: 1794-1804.

-Conrad, S., M. Renninger, J. Hennenlotter, T. Wiesner, L. Just, M. Bonin, W. Aicher, H.J. Bühring, U. Mattheus, A. Mack, H.J. Wagner, S. Minger, M. Matzkies, M. Reppel, J. Hescheler, K.D. Sievert, A. Stenzl, T. Skutella (2008) Generation of pluripotent stem cells from adult human testis. Nature 456: $344-$ 349.

Cooke, J.E., I. Godin, C. Ffrench-Constant, J. Heasman, C.C. Wylie (1993) Culture and manipulation of primordial germ cells. Methods Enzymol 225: 37-58.

-Dell'Era, P., R. Ronca, L. Coco, S. Nicoli, M. Metra, M. Presta (2003) Fibroblast growth factor receptor-1 is essential for in vitro cardiomyocyte development. Circ Res 93: 414-420.

Drukker, M., G. Katz, A. Urbach, M. Schuldiner, G. Markel, J. Itskovitz-Eldor, B. Reubinoff, O. Mandelboim, N. Benvenisty (2002) Characterization of the expression of MHC proteins in human embryonic stem cells. Proc Natl Acad Sci USA 99: 9864-9869.

Dyer, L.A., M.L. Kirby (2009) The role of secondary heart field in cardiac development. Dev Biol 336: 137-144.
Eid, H., D. Larson, J. Springhorn, M. Attawia, R. Nayak, T. Smith, R. Kelly (1992) Role of epicardial mesothelial cells in the modification of phenotype and function of adult rat ventricular myocytes in primary coculture. Circ Res 71: 40-50.

Engel, J. (1989) EGF-like domains in extracellular matrix proteins: localized signals for growth and differentiation? FEBS Lett 251: $1-7$.

-Evans, M.J., M.H. Kaufman (1981) Establishment in culture of pluripotential cells from mouse embryos. Nature 292: 154-156.

Gittenberger-de Groot, A.C., M.P. Vrancken Peeters, M.M. Mentink, R.G. Gourdie, R.E. Poelmann (1998) Epicardium-derived cells contribute a novel population to the myocardial wall and the atrioventricular cushions. Circ Res 82: 1043-1052.

Goumans, M.J., T.P. de Boer, A.M. Smits, L.W. van Laake, P. van Vliet, C.H. Metz, T.H. Korfage, K.P. Kats, R. Hochstenbach, G. Pasterkamp, M.C. Verhaar, M.A. van der Heyden, D. de Kleijn, C.L. Mummery, T.A. van Veen, J.P. Sluijter, P.A. Doevendans (2008) TGF- $\beta 1$ induces efficient differentiation of human cardiomyocyte progenitor cells into functional cardiomyocytes in vitro. Stem Cell Res 1: 138-149.

Guan, K., K. Nayernia, L.S. Maier, S. Wagner, R. Dressel, J.H. Lee, J. Nolte, F. Wolf, M. Li, W. Engel, G. Hasenfuss (2006) Pluripotency of spermatogonial stem cells from adult mouse testis. Nature 440: 1199-1203.

Guan, K., S. Wagner, B. Unsold, L.S. Maier, D. Kaiser, B. Hemmerlein, K. Nayernia, W. Engel, G. Hasenfuss (2007) Generation of functional cardiomyocytes from adult mouse spermatogonial stem cells. Circ Res 100: $1615-1625$.

Guo, X.M., Y.S. Zhao, H.X. Chang, C.Y. Wang, L.L. E, X.A. Zhang, C.M. Duan, L.Z. Dong, H. Jiang, J. Li, Y. Song, X.J. Yang (2006) Creation of engineered cardiac tissue in vitro from mouse embryonic stem cells. Circulation 113: 2229-2237.

- Harvey, R.P. (2002) Patterning the vertebrate heart. Nat Rev Genet 3: 44-556.

Helm, C.-L.E., A. Zisch, M.A. Swartz (2007) Engineered blood and lymphatic capillaries in 3 -D VEGF-fibrin-collagen matrices with interstitial flow. Biotechnol Bioeng 96: 167-176.

-Hirota, H., J. Chen, U.A. Betz, K. Rajewsky, Y. Gu, J. Ross, W. Müller, K.R. Chien (1999) Loss of a gp130 cardiac muscle cell survival pathway is a critical event in the onset of heart failure during biomechanical stress. Cell 97: 189-198.

Hirota, H., K. Yoshida, T. Kishimoto, T. Taga (1995) Continuous activation of gp130, a signal-transducing receptor component for interleukin 6-related cytokines, causes myocardial hypertrophy in mice. Proc Natl Acad Sci USA 92: 4862-4866.
Hiruma, T., R. Hirakow (1989) Epicardial formation in embryonic chick heart: computeraided reconstruction, scanning, and transmission electron microscopic studies. Am J Anat 184: 129-138.

Ho, E., Y. Shimada (1978) Formation of the epicardium studied with the scanning electron microscope. Dev Biol 66: 579-585.

Hynes, R.O. (2009) The extracellular matrix: not just pretty fibrils. Science 326: $1216-$ 1219.

Ieda, M., T. Tsuchihashi, K.N. Ivey, R.S. Ross, T.T. Hong, R.M. Shaw, D. Srivastava (2009) Cardiac fibroblasts regulate myocardial proliferation through $\beta 1$ integrin signaling. Dev Cell 16: 233-244.

-Jiang, Z.S., M. Jeyaraman, G.B. Wen, R.R. Fandrich, I.M. Dixon, P.A. Cattini, E. Kardami (2007) High- but not low-molecular weight FGF-2 causes cardiac hypertrophy in vivo: possible involvement of cardiotrophin-1. J Mol Cell Cardiol 42: 222-233.

Jokinen, J., E. Dadu, P. Nykvist, J. Käpylä, D.J. White, J. Ivaska, P. Vehviläinen, H. Reunanen, H. Larjava, L. Häkkinen, J. Heino (2004) Integrin-mediated cell adhesion to type I collagen fibrils. J Biol Chem 279: 31956-31963.

Kakkar, R., R.T. Lee (2010) Intramyocardial fibroblast myocyte communication. Circ Res 106: 47-57.

Kardami, E., K. Detillieux, X. Ma, Z. Jiang, J.J. Santiago, S. Jimenez, P. Cattini (2007) Fibroblast growth factor-2 and cardioprotection. Heart Fail Rev 12: 267-277.

Kattman, S.J., A.D. Witty, M. Gagliardi, N.C. Dubois, M. Niapour, A. Hotta, J. Ellis, G. Keller (2011) Stage-specific optimization of activin/nodal and BMP signaling promotes cardiac differentiation of mouse and human pluripotent stem cell lines. Cell Stem Cell 8: 228-240.

Kehat, I., D. Kenyagin-Karsenti, M. Snir, H. Segev, M. Amit, A. Gepstein, E. Livne, O. Binah, J. Itskovitz-Eldor, L. Gepstein (2001) Human embryonic stem cells can differentiate into myocytes with structural and functional properties of cardiomyocytes. J Clin Invest 108: 407-414.

Kim, K., A. Doi, B. Wen, K. Ng, R. Zhao, P. Cahan, J. Kim, M.J. Aryee, H. Ji, L.I. Ehrlich, A. Yabuuchi, A. Takeuchi, K.C. Cunniff, H. Hongguang, S. McKinney-Freeman, O. Naveiras, T.J. Yoon, R.A. Irizarry, N. Jung, J. Seita, J. Hanna, P. Murakami, R. Jaenisch, R. Weissleder, S.H. Orkin, I.L. Weissman, A.P. Feinberg, G.Q. Daley (2010) Epigenetic memory in induced pluripotent stem cells. Nature 467: 285-290.

Kim, K., P. Lerou, A. Yabuuchi, C. Lengerke, K. Ng, J. West, A. Kirby, M.J. Daly, G.Q. Daley (2007) Histocompatible embryonic stem cells by parthenogenesis. Science 315: 482486. 
Kim, J.B., V. Sebastiano, G. Wu, M.J. AraúzoBravo, P. Sasse, L. Gentile, K. Ko, D. Ruau, M. Ehrich, D. van den Boom, J. Meyer, K. Hübner, C. Bernemann, C. Ortmeier, M. Zenke, B.K. Fleischmann, H. Zaehres, H.R. Schöler (2009) Oct4-induced pluripotency in adult neural stem cells. Cell 136: 411419.

Klug, M.G., M.H. Soonpaa, G.Y. Koh, L.J. Field (1996) Genetically selected cardiomyocytes from differentiating embronic stem cells form stable intracardiac grafts. J Clin Invest 98: 216-224.

Ko, K., M.J. Arauzo-Bravo, N. Tapia, J. Kim, Q. Lin, C. Bernemann, D.W. Han, L. Gentile, P. Reinhardt, B. Greber, R.K. Schneider, S. Kliesch, M. Zenke, H.R. Scholer (2010) Human adult germline stem cells in question. Nature 465: E1.

Ladd, A.N., T.A. Yatskievych, P.B. Antin (1998) Regulation of avian cardiac myogenesis by activin/TGFbeta and bone morphogenetic proteins. Dev Biol 204: 407-419.

Laflamme, M.A., K.Y. Chen, A.V. Naumova, V. Muskheli, J.A. Fugate, S.K. Dupras, H. Reinecke, C. Xu, M. Hassanipour, S. Police, C. O'Sullivan, L. Collins, Y. Chen, E. Minami, E.A. Gill, S. Ueno, C. Yuan, J. Gold, C.E. Murry (2007) Cardiomyocytes derived from human embryonic stem cells in pro-survival factors enhance function of infarcted rat hearts. Nat Biotechnol 25: 1015-1024.

Langer, R., J.P. Vacanti (1993) Tissue engineering. Science 260: 920-926.

-Liao, S., J. Bodmer, D. Pietras, M. Azhar, T. Doetschman, J.E.J. Schultz (2009) Biological functions of the low and high molecular weight protein isoforms of fibroblast growth factor-2 in cardiovascular development and disease. Dev Dyn 238: 249-264.

-Limana, F., A. Zacheo, D. Mocini, A. Mangoni, G. Borsellino, A. Diamantini, R. De Mori, L. Battistini, E. Vigna, M. Santini, V. Loiaconi, G. Pompilio, A. Germani, M.C. Capogrossi (2007) Identification of myocardial and vascular precursor cells in human and mouse epicardium. Circ Res 101: 1255-1265.

Lopez-Sanchez, C., V. Climent, G. Schoenwolf, I. Alvarez, V. Garcia-Martinez (2002) Induction of cardiogenesis by Hensen's node and fibroblast growth factors. Cell Tissue Res 309: 237-249.

Lough, J., M. Barron, M. Brogley, Y. Sugi, D.L. Bolender, X. Zhu (1996) Combined BMP-2 and FGF-4, but neither factor alone, induces cardiogenesis in non-precardiac embryonic mesoderm. Dev Biol 178: 198-202.

Männer, J. (2006) Extracardiac tissues and the epigenetic control of myocardial development in vertebrate embryos. Ann Anat 188: 199-212.

Martin, G.R. (1981) Isolation of a pluripotent cell line from early mouse embryos cultured in medium conditioned by teratocarcinoma. Proc Natl Acad Sci USA 78: 7634-7638.
Mauritz, C., K. Schwanke, M. Reppel, S. Neef, K. Katsirntaki, L.S. Maier, F. Nguemo, S. Menke, M. Haustein, J. Hescheler, G. Hasenfuss, U. Martin (2008) Generation of functional murine cardiac myocytes from induced pluripotent stem cells. Circulation 118: 507-517.

Mikawa, T., R.G. Gourdie (1996) Pericardial mesoderm generates a population of coronary smooth muscle cells migrating into the heart along with ingrowth of the epicardial organ. Dev Biol 174: 221-232.

Mima, T., H. Ueno, D.A. Fischman, L.T. Williams, T. Mikawa (1995) Fibroblast growth factor receptor is required for in vivo cardiac myocyte proliferation at early embryonic stages of heart development. Proc Natl Acad Sci USA 92: 467-471.

Mummery, C., D. Ward-van Oostwaard, P. Doevendans, R. Spijker, S. van den Brink, R. Hassink, M. van der Heyden, T. Opthof, M. Pera, A.B. de la Riviere, R. Passier, L. Tertoolen (2003) Differentiation of human embryonic stem cells to cardiomyocytes: role of coculture with visceral endoderm-like cells. Circulation 107: 2733-2740.

Murry, C.E., G. Keller (2008) Differentiation of embryonic stem cells to clinically relevant populations: lessons from embryonic development. Cell 132: 661-680.

Murtuza, B., J.W. Nichol, A. Khademhosseini (2009) Micro- and nanoscale control of the cardiac stem cell niche for tissue fabrication. Tissue Eng Part B Rev 15: 443-454.

Naito, H., I. Melnychenko, M. Didie, K. Schneiderbanger, P. Schubert, S. Rosenkranz, T. Eschenhagen, W.H. Zimmermann (2006) Optimizing engineered heart tissue for therapeutic applications as surrogate heart muscle. Circulation 114 (1 suppl): I72-I78.

Nakajima, Y., T. Yamagishi, K. Ando, H. Nakamura (2002) Significance of bone morphogenetic protein- 4 function in the initial myofibrillogenesis of chick cardiogenesis. Dev Biol 245: 291-303.

Niessen, K., A. Karsan (2008) Notch signaling in cardiac development. Circ Res 102: 11691181.

Niwa, H. (2007) How is pluripotency determined and maintained? Development 134: 635646.

Noseda, M., T. Peterkin, F.C. Simoes, R. Patient, M.D. Schneider (2011) Cardiopoietic factors: extracellular signals for cardiac lineage commitment. Circ Res 108: 129-152.

Noseda, M., M.D. Schneider (2009) Fibroblasts inform the heart: control of cardiomyocyte cycling and size by age-dependent paracrine signals. Dev Cell 16: 161-162.

Olson, E.N. (2006) Gene regulatory networks in the evolution and development of the heart. Science 313: 1922-1927.

Opelz, G., T. Wujciak, B. Dohler, S. Scherer, J. Mytilineos (1999) HLA compatibility and organ transplant survival: Collaborative Transplant Study. Rev Immunogenet 1: 334342.
Paige, S.L., T. Osugi, O.K. Afanasiev, L. Pabon, H. Reinecke, C.E. Murry (2010) Endogenous $\mathrm{wnt} / \beta$-catenin signaling is required for cardiac differentiation in human embryonic stem cells. PLoS One 5: el1134.

Prall, O.W., M.K. Menon, M.J. Solloway, Y. Watanabe, S. Zaffran, F. Bajolle, C. Biben, J.J. McBride, B.R. Robertson, H. Chaulet, F.A. Stennard, N. Wise, D. Schaft, O. Wolstein, M.B. Furtado, H. Shiratori, K.R. Chien, H. Hamada, B.L. Black, Y. Saga, E.J. Robertson, M.E. Buckingham, R.P. Harvey (2007) An Nkx2-5/Bmp2/Smad1 negative feedback loop controls heart progenitor specification and proliferation. Cell 128: 947-959.

Radisic, M., H. Park, H. Shing, T. Consi, F.J. Schoen, R. Langer, L.E. Freed, G. VunjakNovakovic (2004) Functional assembly of engineered myocardium by electrical stimulation of cardiac myocytes cultured on scaffolds. Proc Natl Acad Sci USA 101: 1812918134.

-Razvi, E.S. (2010) Conference scene: emerging themes in the stem cells space. Regen Med 5: 197-200.

Rosenblatt-Velin, N., M.G. Lepore, C. Cartoni, F. Beermann, T. Pedrazzini (2005) FGF-2 controls the differentiation of resident cardiac precursors into functional cardiomyocytes. J Clin Invest 115: 1724-1733.

- Samarel, A.M. (2005) Costameres, focal adhesions, and cardiomyocyte mechanotransduction. Am J Physiol Heart Circ Physiol 289: H2291-H2301.

-Schenke-Layland, K., A. Nsair, B. Van Handel, E. Angelis, J.M. Gluck, M. Votteler, J.I. Goldhaber, H.K. Mikkola, M. Kahn, W.R. Maclellan (2011) Recapitulation of the embryonic cardiovascular progenitor cell niche. Biomaterials 32: 2748-2756.

Schroeder, M., S. Niebruegge, A. Werner, E. Willbold, M. Burg, M. Ruediger, L.J. Field, J. Lehmann, R. Zweigerdt (2005) Differentiation and lineage selection of mouse embryonic stem cells in a stirred bench scale bioreactor with automated process control. Biotechnol Bioeng 92: 920-933.

-Shi, Y., C. Desponts, J.T. Do, H.S. Hahm, H.R. Schöler, S. Ding (2008) Induction of pluripotent stem cells from mouse embryonic fibroblasts by Oct 4 and Klf4 with small-molecule compounds. Cell Stem Cell 3: 568-574.

-Shi, Y., J. Massagué (2003) Mechanisms of TGFbeta signaling from cell membrane to the nucleus. Cell 113: 685-700.

Smart, N., S. Bollini, K.N. Dube, J.M. Vieira, B. Zhou, S. Davidson, D. Yellon, J. Riegler, A.N. Price, M.F. Lythgoe, W.T. Pu, P.R. Riley (2011) De novo cardiomyocytes from within the activated adult heart after injury. Nature 474: 640-644.

Smith, T.K., D.M. Bader (2007) Signals from both sides: control of cardiac development by the endocardium and epicardium. Semin Cell Dev Biol 18: 84-89. 
Smith, J.C., B.M. Price, K.V. Nimmen, D. Huylebroeck (1990) Identification of a potent Xenopus mesoderm-inducing factor as a homologue of activin A. Nature 345: 729-731.

-Stadtfeld, M., M. Nagaya, J. Utikal, G. Weir, K. Hochedlinger (2008) Induced pluripotent stem cells generated without viral integration. Science 322: 945-949.

-Sugi, Y., J. Lough (1994) Anterior endoderm is a specific effector of terminal cardiac myocyte differentiation of cells from the embryonic heart forming region. Am J Anat 200: 155-162.

-Swann, K., J.P. Ozil (1994) Dynamics of the calcium signal that triggers mammalian egg activation. Int Rev Cytol 152: 183-222.

-Swijnenburg, R.J., S. Schrepfer, F. Cao, J.I. Pearl, X. Xie, A.J. Connolly, R.C. Robbins, J.C. Wu (2008) In vivo imaging of embryonic stem cells reveals patterns of survival and immune rejection following transplantation. Stem Cells Dev 17: 1023-1029.

Takahashi, N., A. Calderone, N.J. Izzo, T.M. Mäki, J.D. Marsh, W.S. Colucci (1994) Hypertrophic stimuli induce transforming growth factor-beta 1 expression in rat ventricular myocytes. J Clin Invest 94: 14701476.

Takahashi, K., K. Tanabe, M. Ohnuki, M. Narita, T. Ichisaka, K. Tomoda, S. Yamanaka (2007) Induction of pluripotent stem cells from adult human fibroblasts by defined factors. Cell 131: 861-872.

Takehara, N., Y. Tsutsumi, K. Tateishi, T. Ogata, H. Tanaka, T. Ueyama, T. Takahashi, T. Takamatsu, M. Fukushima, M. Komeda, M. Yamagishi, H. Yaku, Y. Tabata, H. Matsubara, H. Oh (2008) Controlled delivery of basic fibroblast growth factor promotes human cardiosphere-derived cell engraftment to enhance cardiac repair for chronic myocardial infarction. J Am Coll Cardiol 52: 1858 1865.

Tam, P.P., D.A. Loebel (2007) Gene function in mouse embryogenesis: get set for gastrulation. Nat Rev Genet 8: 368-381.

Tevosian, S.G., A.E. Deconinck, M. Tanaka, M. Schinke, S.H. Litovsky, S. Izumo, Y. Fujiwara, S.H. Orkin (2000) FOG-2, a cofactor for GATA transcription factors, is essential for heart morphogenesis and development of coronary vessels from epicardium. Cell 101: 729-739.
Thomson, J.A., J. Itskovitz-Eldor, S.S. Shapiro, M.A. Waknitz, J.J. Swiergiel, V.S. Marshall, J.M. Jones (1998) Embryonic stem cell lines derived from human blastocysts. Science 282: 1145-1147.

Tulloch, N.L., V. Muskheli, M.V. Razumova, F.S. Korte, M. Regnier, K.D. Hauch, L. Pabon, H. Reinecke, C.E. Murry (2011) Growth of engineered human myocardium with mechanical loading and vascular coculture. Circ Res 109: 47-59.

Virágh, S., A.C. Gittenberger-de Groot, R.E. Poelmann, F. Káimán (1993) Early development of quail heart epicardium and associated vascular and glandular structures. Anat Embryol (Berl) 188: 381-393.

Wang, X., R.E. Harris, L.J. Bayston, H.L. Ashe (2008) Type IV collagens regulate BMP signalling in Drosophila. Nature 455: 72-77.

Weber, K. (1989) Cardiac interstitium in health and disease: the fibrillar collagen network. J Am Coll Cardiol 13: 1637-1652.

Wijelath, E.S., S. Rahman, M. Namekata, J. Murray, T. Nishimura, Z. Mostafavi-Pour, Y. Patel, Y.Suda, M.J. Humphries, M. Sobel (2006) Heparin-II domain of fibronectin is a vascular endothelial growth factor-binding domain: enhancement of VEGF biological activity by a singular growth factor/matrix protein synergism. Circ Res 99: 853-860.

Wobus, A.M., K. Guan, H.T. Yang, K.R. Boheler (2002) Embryonic stem cells as a model to study cardiac, skeletal muscle, and vascular smooth muscle cell differentiation. Methods Mol Biol 185: 127-156.

Wollert, K.C., K.R. Chien (1997) Cardiotrophin-1 and the role of gp130-dependent signaling pathways in cardiac growth and development. J Mol Med 75: 492-501.

Yakubov, E., G. Rechavi, S. Rozenblatt, D. Givol (2010) Reprogramming of human fibroblasts to pluripotent stem cells using mRNA of four transcription factors. Biochem Biophys Res Commun 394: 189-193.
Yang, L., M.H. Soonpaa, E.D. Adler, T.K. Roepke, S.J. Kattman, M. Kennedy, E. Henckaerts, K. Bonham, G.W. Abbott, R.M. Linden, L.J. Field, G.M. Keller (2008) Human cardiovascular progenitor cells develop from a KDR+ embryonic-stem-cell-derived population. Nature 453: 524-528.

Yu, J., M.A. Vodyanik, K. Smuga-Otto, J. Antosiewicz-Bourget, J.L. Frane, S. Tian, J. Nie, G.A. Jonsdottir, V. Ruotti, R. Stewart, I.I. Slukvin, J.A. Thomson (2007) Induced pluripotent stem cell lines derived from human somatic cells. Science 318: 1917-1920.

Zhang, J., G.F. Wilson, A.G. Soerens, C.H. Koonce, J. Yu, S.P. Palecek, J.A. Thomson, T.J. Kamp (2009) Functional cardiomyocytes derived from human induced pluripotent stem cells. Circ Res 104: e30-e41.

Zhou, H., S. Wu, J.Y. Joo, S. Zhu, D.W. Han, T. Lin, S. Trauger, G. Bien, S. Yao, Y. Zhu, G. Siuzdak, H.R. Schöler, L. Duan, S. Ding (2009) Generation of induced pluripotent stem cells using recombinant proteins. Cell Stem Cell 4: 381-384.

Zhu, W.Z., Y. Xie, K.W. Moyes, J.D. Gold, B. Askari, M.A. Laflamme (2010) Neuregulin/ ErbB signaling regulates cardiac subtype specification in differentiating human embryonic stem cells. Circ Res 107: 776-786.

Zimmermann, W.H. (2011) Embryonic and embryonic-like stem cells in heart muscle engineering. J Mol Cell Cardiol 50: 320-326.

Zimmermann, W.H., I. Melnychenko, T. Eschenhagen (2004) Engineered heart tissue for regeneration of diseased hearts. Biomaterials 25: 1639-1647.

Zimmermann, W.H., I. Melnychenko, G. Wasmeier, M. Didie, H. Naito, U. Nixdorff, A. Hess, L. Budinsky, K. Brune, B. Michaelis, S. Dhein, A. Schwoerer, H. Ehmke, T. Eschenhagen (2006) Engineered heart tissue grafts improve systolic and diastolic function in infarcted rat hearts. Nat Med 12: 452-458.

Zimmermann, W.H., K. Schneiderbanger, P. Schubert, M. Didie, F. Munzel, J.F. Heubach, S. Kostin, W.L. Neuhuber, T. Eschenhagen (2002) Tissue engineering of a differentiated cardiac muscle construct. Circ Res 90: 223230 . 